\title{
Phylogenetic Analysis of a New LL-Diaminopimelic Acid-Containing Coryneform Bacterium from Herbage, Nocardioides plantarum sp. nov.
}

\author{
M. D. COLLINS, ${ }^{*}$ S. COCKCROFT, ${ }^{2}$ AND SALLY WALLBANKS ${ }^{1}$ \\ Department Microbiology, Institute of Food Research, Reading Laboratory, Reading RG6 $2 E F,{ }^{1}$ and \\ Department of Microbiology, University of Reading, Reading RG6 $2 A J^{2}{ }^{2}$ United Kingdom
}

\begin{abstract}
The 16S rRNA gene sequence of a previously undescribed LL-diaminopimelic acid-containing coryneform bacterium isolated from herbage was determined in order to clarify the taxonomic position of this organism. A comparative sequence analysis revealed that the bacterium represents a new line of descent within the genus Nocardioides. On the basis of the results of a phylogenetic analysis and the phenotypic distinctiveness of the organism, a new species, Nocardioides plantarum, is proposed. The type strain is NCIMB 12834.
\end{abstract}

Relatively few species of coryneform bacteria which contain walls based on LL-diaminopimelic acid ( $\left.L L-\mathrm{A}_{2} \mathrm{Pm}\right)$ have been described (13). The currently recognized LL- $\mathrm{A}_{2} \mathrm{pm}$-containing taxa include species of the genus Nocardioides (Nocardioides simplex, Nocardioides albus, Nocardioides jensenii, Nocardioides fastidiosa), Terrabacter tumescens, Aeromicrobium erythreum, and some propionibacteria (Propionibacterium innocuum). However, there is a considerable amount of evidence that LL- $\mathrm{A}_{2} \mathrm{pm}$-containing coryneform bacteria may be relatively common in nature (14) and that the vast majority of these organisms have not been described. During an investigation of the genetic diversity of $\mathrm{LL}_{-} \mathrm{A}_{2} \mathrm{pm}$-containing coryneforms, we determined the almost complete $16 \mathrm{~S}$ (small-subunit) rRNA gene sequence of a previously undescribed thiamine-requiring bacterium that was originally isolated by Grainger (12) from herbage. A comparison of this sequence with the sequences of other $\mathrm{LL}-\mathrm{A}_{2} \mathrm{pm}$-containing coryneform and related taxa indicated that the herbage bacterium represents a new line of descent within the genus Nocardioides, for which the name Nocardioides plantarum sp. nov. is proposed.

\section{MATERIALS AND METHODS}

Cultures and cultivation. Strains Grainger $\mathrm{J} 70^{\mathrm{T}}$ ( $\mathrm{T}=$ type strain) and Grainger J6, which were originally isolated from herbage (12), were received from J. M. Grainger, University of Reading, Reading, United Kingdom. These organisms were routinely cultivated in EYPB broth and EYPB agar (see reference 4 for compositions of media) at $25^{\circ} \mathrm{C}$ and were maintained at $10^{\circ} \mathrm{C}$.

Biochemical and physiological characterization. The ability to grow in the presence of various concentrations of $\mathrm{NaCl}$ was determined in EYPB broth containing 5, 7.5, and $10 \%$ (wt/vol) $\mathrm{NaCl}$. Nitrate reduction was examined by using EYPB medium in which the mineral base contained $1 \mathrm{~g}$ of potassium nitrate per liter but no ammonium sulfate. Catalase and oxidase tests were performed with growth from 3-day cultures grown on EYPB agar (5). Casein (1\%, wt/vol) and gelatin $(0.4 \%$, wt/vol) hydrolysis tests were performed on EYPB agar, and the results were detected with Frazier's reagent $(10)$. Starch $(0.2 \%$, wt/ vol) hydrolysis was examined by using the same medium and

* Corresponding author. Mailing address: Institute of Food Research, Reading Laboratory, Earley Gate, Whiteknights Road, Reading RG6 2EF, United Kingdom. Phone: (0734) 357226. Fax: (0734) 267917. was detected with Lugol's iodine solution. Hydrolysis of Tweens $(1 \%$, vol/vol) was determined in EYPB agar supplemented with $0.1 \mathrm{~g}$ of $\mathrm{CaCl}_{2}$ per liter. The incubation temperature in all cases was $25^{\circ} \mathrm{C}$.

Carbon utilization tests were performed in basal medium containing (per liter of mineral base E [16]) $0.2 \mathrm{~g}$ of Bacto Yeast Extract (Difco, West Molesey, United Kingdom), $12 \mathrm{~g}$ of agar no. 1 (Oxoid, Basingstoke, United Kingdom), $2 \mu \mathrm{g}$ of vitamin $B_{12}, 10 \mathrm{mg}$ of sodium glutamate, and $10 \mathrm{mg}$ of methionine. Water-soluble substrates were filter sterilized, whereas insoluble substrates were autoclaved at $115^{\circ} \mathrm{C}$ for 5 $\min$. With the exception of phenol $(0.025 \mathrm{~g} /$ liter $)$, thymine $(5$ $\mathrm{g} /$ liter), and uracil ( $5 \mathrm{~g} /$ liter $)$, the substrates were tested at a concentration of $1 \mathrm{~g} /$ liter of basal medium. Plates were incubated at $25^{\circ} \mathrm{C}$ and were examined after 7,10 and 21 days. A positive result was recorded when the growth on medium containing substrate was unequivocally greater than the growth on basal medium.

Menaquinone analysis. Menaquinones were extracted from dry cells, purified by thin-layer chromatography, and characterized as described previously (3).

DNA studies. Chromosomal DNA was isolated from wet packed cells as described by Pitcher et al. (17). DNA base composition was estimated by thermal denaturation in standard saline citrate as described by Garvie (11), using DNA from Escherichia coli $\mathrm{K}-12(51.5 \mathrm{~mol} \% \mathrm{G}+\mathrm{C})$ as the standard. Chromosomal hybridization was performed as described by Farrow et al. (7).

Determination of 16S rRNA gene sequences. The 16S rRNA gene was amplified by a PCR in which universal primers pA (positions 8 to $28 ; E$. coli numbering) and $\mathrm{pH}^{*}$ (positions 1542 to 1522) (1) were used. Approximately $2 \mu \mathrm{g}$ of chromosomal DNA was amplified in a total volume of $100 \mu$ l containing $1 \mathrm{U}$ of Taq polymerase (Advanced Biotechnologies, Ltd., West Hampstead, United Kingdom). The reaction involved 36 cycles of denaturation at $92^{\circ} \mathrm{C}$ for $2 \mathrm{~min}$, primer annealing at $55^{\circ} \mathrm{C}$ for $1 \mathrm{~min}$, and primer extension at $72^{\circ} \mathrm{C}$ for $1.5 \mathrm{~min}$. The DNA was extracted with chloroform and purified with a Magic DNA clean-up system (Promega Corp.) according to the manufacturer's instructions. A qualitative analysis of the DNA fragments was performed by agarose gel electrophoresis. The sequence of the amplified product was determined with $\alpha-{ }^{35} \mathrm{~S}$ labeled dATP and a Sequenase version 2.0 sequencing kit (Cambridge Bioscience, Cambridge, United Kingdom). The reaction products were separated on $55-\mathrm{cm}$ wedge-shaped (0.2to $0.6-\mathrm{mm}$ ) $6 \%$ acrylamide- $7 \mathrm{M}$ urea gels at $55^{\circ} \mathrm{C}$ with an LKB 
TABLE 1. Characteristics useful for differentiating $N$. plantarum sp. nov. from other Nocardioides species and T. tumescens

\begin{tabular}{|c|c|c|c|c|c|c|c|}
\hline Characteristic & N. plantarum & N. albus & N. luteus & N. fastidiosa & $N$. jensenii & N. simplex & T. tumescens \\
\hline Aerial mycelium & - & + & + & - & - & - & - \\
\hline \multicolumn{8}{|l|}{$\begin{array}{l}\text { Utilization of the following compounds } \\
\text { as sole carbon and energy sources: }\end{array}$} \\
\hline Azelate & - & + & + & + & + & + & + \\
\hline Cellobiose & + & + & + & + & - & - & + \\
\hline Fructose & + & + & + & + & - & - & + \\
\hline Histamine & - & $\mathrm{V}^{a}$ & - & V & $\mathrm{ND}^{b}$ & + & - \\
\hline Malonate & - & + & + & - & - & + & + \\
\hline Maltose & + & + & + & - & + & - & + \\
\hline L-Proline & V & + & + & V & - & + & + \\
\hline Phenol & - & - & + & - & ND & + & - \\
\hline L-Rhamnose & + & + & - & - & + & - & $\mathrm{V}$ \\
\hline Tetradecane & V & + & + & + & - & + & - \\
\hline Thymine & - & - & - & - & + & + & + \\
\hline Uracil & - & - & - & - & + & + & + \\
\hline Suberate & - & + & + & + & + & + & $\mathrm{V}$ \\
\hline Growth in glucose-mineral salts medium & - & + & + & - & + & + & - \\
\hline $\begin{array}{l}\text { Growth in glucose-mineral salts medium } \\
\text { containing thiamine }\end{array}$ & + & - & - & - & - & - & + \\
\hline
\end{tabular}

${ }^{a} \mathrm{~V}$, variable.

${ }^{b} \mathrm{ND}$, not determined.

Macrophor 2010 sequencing unit (Pharmacia, Milton-Keynes, United Kingdom) operated at $50 \mathrm{~W}$ per gel. The sequences generated were aligned with sequences of other actinomycetes obtained from the GenBank (EMBL) data library, and similarity values were determined by using the Wisconsin Molecular Biology Package (6). Nucleotide substitution rates $\left(K_{\text {nuc }}\right.$ values) were calculated, and an unrooted phylogenetic tree was produced by using the algorithm of Fitch and Margoliash (8, 9).

Nucleotide sequence accession number. The $16 \mathrm{~S}$ rRNA gene sequence determined in this study has been deposited in the GenBank data library under accession number X69973.

\section{RESULTS AND DISCUSSION}

The cells of the two $\mathrm{LL}-\mathrm{A}_{2} \mathrm{pm}$-containing strains which we studied were gram-positive, nonmotile, irregular, short rods. Coccoid forms were also formed. Unlike N. albus and Nocardioides luteus, neither substrate mycelium nor primary mycelium was produced. The two strains were similar to Nocardioides spp. and T. tumescens in being obligately aerobic, but they more closely resembled the latter taxon in requiring thiamine for growth in glucose-mineral salts medium. A wide range of organic compounds were utilized as sole carbon and energy sources by the herbage isolates (see species description below). Both strains were readily distinguished from previously described Nocardioides spp. because they did not utilize azelate and suberate, while the inability of these strains to utilize thymine and uracil distinguished them from $T$. tumescens. Other characteristics that are useful for differentiating the previously undescribed strains from Nocardioides spp. and $T$. tumescens are shown in Table 1.

The $16 \mathrm{~S}$ rRNA gene of strain Grainger $\mathrm{J} 70^{\mathrm{T}}$ was amplified in vitro, and its nucleotide sequence was determined. The derived $16 \mathrm{~S}$ rRNA primary structure is shown in Fig. 1. The sequence of a short fragment (approximately position 50 to position 500, which included diagnostic variable regions V1 through V3) of the 16S rRNA gene of strain Grainger J6, which belonged to the same phenotypic group (12) as Grainger $\mathrm{J} 70^{\mathrm{T}}$, was also determined; this sequence was found to be identical to the sequence of strain Grainger $\mathbf{J} 70^{\mathrm{T}}$, demonstrating that there is a close genotypic affinity between these two herbage isolates. These findings were confirmed by the results of chromosomal DNA-DNA pairing experiments, which revealed that there is $80 \%$ complementarity between strains Grainger $\mathrm{J} 70^{\mathrm{T}}$ and Grainger J6, indicating that these organisms are members of the same genomic species. We observed significantly lower levels of DNA relatedness between strain Grainger $\mathrm{J}^{\mathrm{T}} 0^{\mathrm{T}}$ and

TTCTACGGAGAGTTTGATCCTGGCTCAGGACGAACGCTGGCGGCGTGCTTGCAAGTCGAGCGGTAAGGCACTTCGGTGTACACGAGCGGCGAACGGGTGA GTAACACGTGAGTAATCTGCCCTTCACTCTGGGATAAGCACTGGAAAGGGTGTCTAATACCGGATACGACGCACTCACGCATGTGATGTGTGTGGAAACT TTTGTGGGTGGGGGATGTGCTCGCGGCCTATCAGCTTGTTGGTGGGGTAATGGCCTACCAAGGCTTCGACGGGTAGCCGGCCTGAGAGGGTGACCGGCCA CACTGGGACTGAGACACGGCCCAGACTCCTACGGGAGGCAGCAGTGGGGAATATTGGACAATGGGCGGAAGCCTGATCCAGCAACGCCGCGTGAGGGATG ACGGCCTTCGGGTTGTAAACCTCTTTCAGTATCGACGAAGCGNNCGTGTGNGTGGTGACGGTAGGTACAGAAGAAGCACCGGCCAACTACGTGCCAGCAG CCGCGGTAATACGTAGGGTGCGAGCGTTGTCCGGAATTATTGGGCGTAAAGGGCTCGTAGGTGGTTTGTCGCGTCGGGAGTGAAAACACTGGGCTTAACC GAGTGCTTGCTTTCGATACGGGCAGACTTGAGGCATTGAGGGGAGAACGGAATTCCTGGTGTAGCGGTGAAATGCGCAGATATCAGGAGGAACACCGGTG GCGAAGGCGGTTCTCTGGCAATGTTCTGACGCTGAGGAGCGAAAGTGTGGGGAGCGAACAGGATTAGATACCCTGGTAGTCCACACCGTAAACGTTGGGC GCTAGGTGTGGGGCCNATTCCACGGGTTCCGTGCCGCAGCTAACGCATTAAGCGCCCCGCCTGGGGAGTACGGCCGCAAGGCTAAAACTCAAAGGAATTG ACGGGGGCCCGCACAAGCGGCGGAGCATGCGGATTAATTCGATGCAACGCGAAGAACCTTACCTGGGTTTGACATACACCCTGCCGCCTCAGAGATGGGG CTTCTTTTGNNNGGTGTACAGGTGGTGCATGGCTGTCGTCAGCTCGTGTCGTGAGATGTTGGGTTAAGTCCCGCAACGAGCGCAACCCTCGTTCTATGTT GCCAGCACGTCCTTCGGGATGGTGGGGACTCATAGGAGACTGCCGGGGTCAACTCGGAGGAAGGTGGGGATGACGTCAAGTCATCATGCCCCTTATGTCC AGGGCTTCACGCATGCTACAATGGCCGGTACAAAGGGCTGCGATCCCGTGAGGGGGAGCGAATCCCAAAAAGCCGGTCTCAGTTCGGATTGGGGTCTGCA ACTCGACCCCATGAAGTCGGAGTCGCTAGTNATCCGAGATCAGCAACGCTGCGGTGAATACGTTCCCGGGCCTTGTACACACCGNNCGTCANGTCACGAA AGTCGGCAACACCCGAAGCNAGTGGCCTAACCACCTTGTGTGGGGGGAGCTGTCGAAGGTGGGGCTGGCGATTGGGACGAAGTCGGTAACAAGGTAGCCG TACCGGAAGGTG

FIG. 1. Derived 16S rRNA gene sequence of $N$. plantarum Grainger $\mathrm{J}^{\mathrm{T}}$. 
TABLE 2. Levels of sequence similarity for a 1,266-nucleotide region of 16S rRNAs of Nocardioides species and other related taxa

\begin{tabular}{|c|c|c|c|c|c|c|c|c|c|c|c|c|c|}
\hline \multirow[b]{2}{*}{ Species } & \multirow[b]{2}{*}{$\begin{array}{c}\text { Accession } \\
\text { no. }^{.}\end{array}$} & \multicolumn{12}{|c|}{$\%$ Sequence similarity } \\
\hline & & 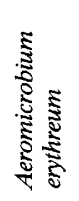 & 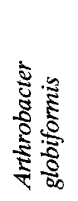 & 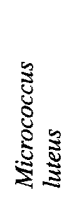 & 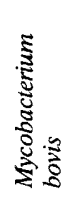 & 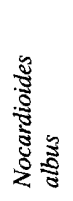 & 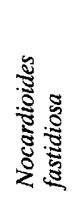 & 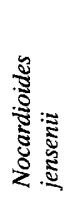 & 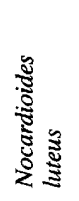 & 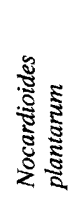 & 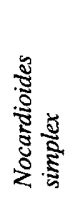 & 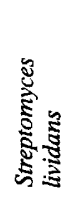 & 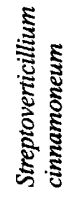 \\
\hline Aeromicrobium erythreum & M37200 & & & & & & & & & & & & \\
\hline Arthrobacter globiformis & M23411 & 89.2 & & & & & & & & & & & \\
\hline Micrococcus luteus & M38242 & 89.3 & 95.2 & & & & & & & & & & \\
\hline Mycobacterium bovis & X55589 & 88.4 & 86.8 & 87.4 & & & & & & & & & \\
\hline Nocardioides albus & X53189 & 91.3 & 87.7 & 88.1 & 87.3 & & & & & & & & \\
\hline Nocardioides fastidiosa & X53189 & 98.0 & 88.9 & 88.9 & 88.5 & 91.8 & & & & & & & \\
\hline Nocardioides jensenii & X53214 & 93.4 & 88.2 & 88.7 & 88.7 & 94.7 & 93.7 & & & & & & \\
\hline Nocardioides luteus & X53212 & 91.2 & 87.6 & 88.1 & 87.4 & 98.8 & 91.8 & 94.2 & & & & & \\
\hline Nocardioides plantarum & X69973 & 91.8 & 86.7 & 87.8 & 87.6 & 92.2 & 92.3 & 92.4 & 92.2 & & & & \\
\hline Nocardioides simplex & X53213 & 92.3 & 89.7 & 89.5 & 89.6 & 95.7 & 92.7 & 94.4 & 95.4 & 93.5 & & & \\
\hline Streptomyces lividans & Y00484 & 89.6 & 88.8 & 89.8 & 86.8 & 88.1 & 89.4 & 89.4 & 87.7 & 87.9 & 88.6 & & \\
\hline Streptoverticillium cinnamoneum & X53165 & 89.7 & 88.7 & 89.2 & 87.4 & 86.7 & 88.5 & 88.5 & 86.5 & 88.3 & 88.8 & 95.8 & \\
\hline Terrabacter tumescens & X53215 & 89.2 & 92,1 & 92.3 & 89.3 & 89.3 & 88.7 & 89.3 & 89.4 & 89.0 & 90.0 & 89.4 & 88.4 \\
\hline
\end{tabular}

${ }^{a}$ EMBL-GenBank nucleotide sequence accession numbers.

other Nocardioides spp. (N. albus NCIMB $11454^{\mathrm{T}}, 22 \% ; N$. jensenii NCIMB $9770^{\mathrm{T}}, 27 \%$; $N$. luteus NCIMB $11455^{\mathrm{T}}, 21 \%$; N. simplex NCIMB $8929^{\mathrm{T}}, 29 \%$ ).

The 16S rRNA sequence of strain Grainger $\mathrm{J}^{\mathrm{T}} \mathrm{T}$ was aligned and compared with the $16 \mathrm{~S}$ rRNA sequences of other high$\mathrm{G}+\mathrm{C}$-content actinomycetes available from the GenBank data library. Sequence similarity calculations revealed that the previously undescribed $\mathrm{LL}-\mathrm{A}_{2} \mathrm{pm}$-containing coryneform bacterium exhibited an affinity for the "Nocardioides branch" of nonsporulating actinomycetes. Table 2 shows the similarity values for a region that is approximately 1,266 nucleotides long (from positions 60 to position $1346 ; E$. coli numbering system) for the new sequence and the sequences of members of the Nocardioides branch and related species. The highest levels of sequence similarity were observed with Nocardioides species $(2,3)$ and the recently described organism $A$. erythreum (15). A significantly lower level of relatedness was observed with the LL-A $\mathrm{A}_{2}$ pm-containing coryneform bacterium $T$. tumescens (2). A tree depicting the position of the previously undescribed bacterium within the Nocardioides branch is shown in Fig. 2 .

The 16S rRNA sequence analysis clearly showed that the

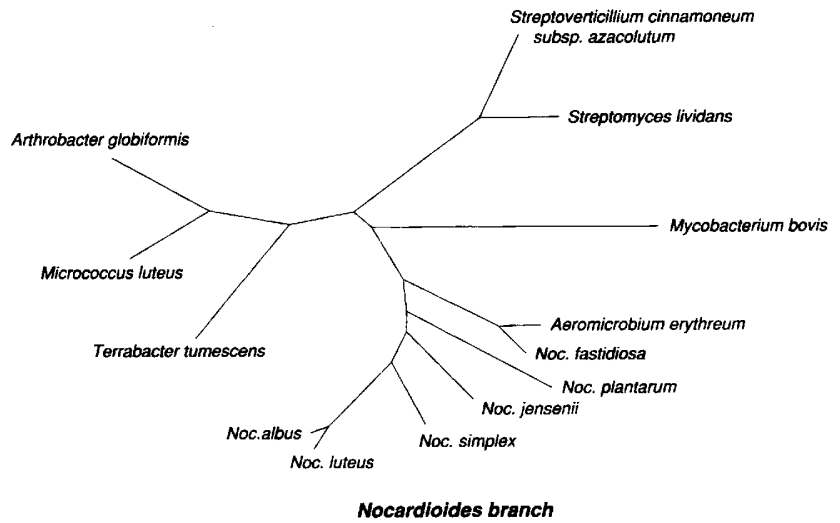

FIG. 2. Phylogenetic network showing the position of N. plantarum within the genus Nocardioides. Noc., Nocardioides. previously undescribed LL- $\mathrm{A}_{2}$ pm-containing coryneform bacterium isolated from herbage is phylogenetically a member of the genus Nocardioides. Its 16S rRNA evolutionary distances from other Nocardioides species were approximately 6.5 to $8 \%$, values which are great enough to warrant description as a distinct species in the genus. The proposal to place this organism in a new species is supported by its phenotypic distinctiveness. This organism requires thiamine as the only growth factor in glucose-mineral salts media (12). This requirement, together with the inability to utilize azelate and suberate, distinguishes the herbage bacterium from all other Nocardioides species. Therefore, we propose that the LL- $\mathrm{A}_{2}$ pm-containing coryneform bacterium should be classified in the genus Nocardioides as Nocardioides plantarum sp. nov.

Description of Nocardioides plantarum sp. nov. Nocardioides plantarum (plan. tar' um. M. L. gen. pl. n. plantarum, of plants). Cells are gram-positive, short rods; coccoid forms also occur. Neither substrate mycelium nor primary mycelium is formed. Colonies are circular, entire, convex, smooth, shiny, and nonpigmented. Cells are nonmotile. Growth occurs at 5 and $30^{\circ} \mathrm{C}$, but not at $37^{\circ} \mathrm{C}$ or in the presence of $5 \% \mathrm{NaCl}$. Strictly aerobic. Thiamine is required for growth. A wide range of organic compounds are utilized as sole or principal carbon and energy sources for growth; these compounds include cellobiose, fructose, glycerol, glucose, maltose, melezitose, L-rhamnose, sucrose, trehalose, D-xylose, isobutyrate, propionate, fumarate, and succinate. L-Arabinose, D-galactose, histidine, histamine, malonate, phenol, azelate, suberate, crotonate, pentoate, thymine, and uracil are not utilized. Some strains utilize L-proline and tetradecane. Casein, Tween 40, Tween 60, Tween 80, and gelatin are hydrolyzed. Cellulose, chitin, urea, starch, and hippurate are not hydrolyzed. Nitrate is not reduced. The cell wall murein contains $L L-A_{2} p m$ as the diamino acid. MK-8( $\left.\mathrm{H}_{4}\right)$ is the main menaquinone component; a minor amount of $\mathrm{MK}-7\left(\mathrm{H}_{4}\right)$ is also produced. The cellular fatty acids are composed of saturated, unsaturated, and iso-, anteiso-, and 10-methyl-branched types. Small amounts of 2-hydroxy fatty acids are also synthesized. The $G+C$ content of the DNA is $69 \mathrm{~mol} \%$ (as determined by the thermal denaturation method). Isolated from herbage. The type strain is NCIMB 12834 (= Grainger J70). 
Description of the type strain. The description of the type strain corresponds to that of the species given above, except that L-proline and tetradecane are not utilized.

\section{ACKNOWLEDGMENTS}

We are grateful to J. M. Grainger for the gift of cultures and to R. Kroppenstedt for menaquinone data.

We thank the EEC (Microbial Diversity Network; grant ERB CHRXCT930194) for supporting this work.

\section{REFERENCES}

1. Boddinghaus, B., J. Wolters, W. Heikens, and E. C. Böttger. 1990. Phylogenetic analysis and identification of six different serovars of Mycobacterium intracellulare at the molecular level. FEMS Microbiol. Lett. 70:197-204.

2. Collins, M. D., M. Dorsch, and E. Stackebrandt. 1989. Transfer of Pimelobacter tumescens to Terrabacter gen. nov. as Terrabacter tumescens comb. nov. and Pimelobacter jensenii to Nocardioides as Nocardioides jensenii comb. nov. Int. J. Syst. Bacteriol 39:1-6.

3. Collins, M. D., and E. Stackebrandt. 1989. Molecular taxonomic studies on some LL-diaminopimelic acid-containing coryneforms from herbage: description of Nocardioides fastidiosa sp. nov. FEMS Microbiol. Lett. 57:289-294.

4. Cure, G. L., and R. M. Keddie. 1973. Methods for the morphological examination of aerobic coryneform bacteria. Soc. Appl. Bacteriol. Tech. Ser. 7:123-135.

5. Davis, G. H. G. 1955 . The classification of lactobacilli from the human mouth. J. Gen. Microbiol. 13:481-493.

6. Devereux, J., P. Haeberli, and D. Smithies. 1984. A comprehensive set of sequence programs for the VAX. Nucleic Acids Res. 12:387-395.

7. Farrow, J. A. E., D. Jones, B. A. Phillips, and M. D. Collins. 1983.
Taxonomic studies on some group D streptococci. J. Gen. Microbiol. 129:1423-1432.

8. Felsenstein, J. 1982. Numerical methods for inferring evolutionary trees. Q. Rev. Biol. 57:379-404.

9. Fitch, W. M., and E. Margoliash. 1967. Construction of phylogenetic trees: a method based on mutation distances as estimated from cytochrome $c$ sequences is of general applicability. Science 155:279-284.

10. Frazier, W. C. 1926. A method for detecting changes in gelatin due to bacteria. J. Infect. Dis. 39:302.

11. Garvie, E. I. 1978. Streptococcus raffinolactis Orla-Jensen and Hansen, a group N streptococcus found in raw milk. Int. J. Syst. Bacteriol. 28:190-193.

12. Grainger, J. M. 1963. Studies on coryneform bacteria from soil and herbage. Ph.D. thesis. University of Reading, Reading, United Kingdom.

13. Keddie, R. M., and G. L. Cure. 1977. The cell wall composition and distribution of free mycolic acids in named strains of coryneform bacteria and in isolates from various natural sources. J. Appl. Bacteriol. 42:229-252.

14. Keddie, R. M., B. G. S. Leask, and J. M. Grainger. 1966. A comparison of coryneform bacteria from soil and herbage: cell wall composition and nutrition. J. Appl. Bacteriol. 29:17-43.

15. Miller, E. S., C. R. Woese, and S. Brenner. 1991. Description of the erythromycin-producing bacterium Arthrobacter sp. strain NRRL B-3381 as Aeromicrobium erythreum gen. nov., sp. nov. Int. J. Syst. Bacteriol. 41:363-368.

16. Owens, J. D., and R. M. Keddie. 1969. The nitrogen nutrition of soil and herbage coryneform bacteria. J. Appl. Bacteriol. 32:338347.

17. Pitcher, D. G., N. A. Saunders, and R. J. Owen. 1989. Rapid extraction of bacterial genomic DNA with guanidium thiocyanate. Lett. Appl. Microbiol. 8:151-156. 